\title{
Educação religiosa e empática em Edith Stein. A vida como plenitude
}

\author{
Clélia Peretti* \\ Sonia Maria Gaio** \\ Valdirlei Augusto Chiquito***
}

\section{Resumo}

Neste artigo, discutem-se os fundamentos antropológico-teológicos da educação religiosa em Edith Stein, proposta pedagógica, vias de acesso à fé, finalidade da educação, a relação empática e a resposta à fé. A pesquisa possui caráter bibliográfico, enfoca a constituição da pessoa humana, sua essência, origem e finalidade. A pessoa é constituída de corpo, psique e espírito. É um ser espiritual, livre, capaz de atos e de consciência de si mesmo. A pedagogia de Edith Stein fundamenta-se na antropologia filosófico-teológica e numa ontologia da pessoa humana e também no horizonte da educação religiosa está a verdade Revelada. Aquilo que a fé cristã diz sobre a pessoa humana constitui o fundamento teorético irrenunciável para a sua constituição. As vivências da educação e seus métodos necessitam do complemento da fé. A empatia, a relação interpessoal e a intersubjetiva ampliam o itinerário pedagógico e contribuem no colhimento da dimensão espiritual e na vivência da sua fé. A finalidade da educação religiosa é conduzir à adesão a Jesus Cristo. Educar para a fé significa revelar, na Pessoa de Cristo, Verbo Encarnado e Filho de Deus, todo o desígnio eterno de Deus. Todo aquele que é chamado a "ensinar Cristo" deve, por primeiro, conhecer Jesus Cristo. A educação religiosa apresenta-se como o espaço para restaurar a aliança entre os esforços do ser humano e a graça divina. O maior educador não é o ser humano, mas Deus. É na relação entre Deus e o educador humano que se alcança a máxima contribuição da constituição da pessoa e insere-se a resposta ao chamamento de Deus à fé.

Palavras-chave: Educação religiosa. Relação empática. Vias de acesso à fé. Catequese de Adultos.

* Doutora em Teologia pela Escola Superior de Teologia EST, São Leopoldo-RS. Pósdoutorado em Fenomenologia no Centro Italiano di Ricerche Fenomenologiche e Pontifícia Universidade Lateranense - Roma. Docente e pesquisadora no Curso do Bacharelado de Teologia e no Programa de Pós-Graduação Mestrado e Doutorado em Teologia - PPGT da PUCPR.cpkperetti@gmail.com

** Graduado em Teologia pela Pontifícia Universidade Católica do Paraná. soniagaio@yahoo. com.br

*** Mestrando em Teologia e graduado em Filosofia pela Pontifícia Universidade Católica do Paraná. chiquito72@gmail.com 


\section{Religious and Empathic Education in Edith Stein: Life as Plenitude Abstract}

In this article, we discuss the anthropological-theological foundations of religious education in Edith Stein, pedagogical proposal, ways of access to faith, the purpose of education, the empathic relationship and the response to faith. The research has a bibliographic character, focusing on the constitution of the human person, its essence, origin and purpose. The person is constituted, body, psyche and spirit. Edith Stein's pedagogy is based on a philosophical-theological anthropology and an ontology of the human person, and on the horizon of religious education is the revealed truth. What the Christian faith says about the human person constitutes the theorethical foundation for its constitution. The experiences of education and its methods need the complement of faith. Empathy, interpersonal and intersubjective relationships broaden the pedagogical itinerary and contribute to the harvesting of the spiritual dimension and the living of their faith. The purpose of religious education is to lead to adherence to Jesus Christ. To educate to faith means to reveal, in the Person of Christ, the Incarnate Word and Son of God, the whole eternal plan of God. Everyone who is called to "teach Christ" must first know Jesus Christ. Religious education presents itself as the space to restore the covenant between human efforts and divine grace. The greatest educator is not the human being, but God. It is in the relationship between God and the human educator that the maximum contribution of the person's constitution is achieved and the response to God's call to faith is inserted.

Keywords: Religious education. Empathic relationship. Pathways of access to faith. Adult Catechesis.

\section{Educación religiosa y empática en Edith Stein: la vida como plenitud}

\section{Resumen}

En este artículo se discuten los fundamentos antropológico-teológicos de la educación religiosa en Edith Stein, propuesta pedagógica, formas de acceder a la fe, finalidad de la educación, la relación empática y la respuesta a la fe. La investigación tiene carácter bibliográfico, centrándose en la constitución de la persona humana, su esencia, origen y finalidad. La persona está constituida por cuerpo, psique y espíritu. Es un ser espiritual, libre, capaz de actuar y de autoconciencia. La pedagogía de Edith Stein se basa en la antropología filosófico-teológica y una ontología de la persona humana y también en el horizonte de la educación religiosa está la Verdad Revelada. Lo que la fe cristiana dice sobre la persona humana constituye el fundamento teórico indispensable para su constitución. Las experiencias de la educación y sus métodos necesitan el complemento de la fe. La empatía, las relaciones interpersonales e intersubjetivas amplían el itinerario pedagógico y contribuyen al encuentro de la dimensión espiritual y la vivencia de su fe. El propósito de la educación religiosa es llevar a la adhesión a Jesucristo. Educar para la fe significa revelar, en la Persona de Cristo, Verbo Encarnado e Hijo de Dios, todo el designio eterno de Dios. Todos los que son llamados a "enseñar a Cristo" deben 
conocer primero a Jesucristo. La educación religiosa se presenta como un espacio para restaurar la alianza entre el esfuerzo humano y la gracia divina. El mayor educador no es el ser humano, sino Dios. Es en la relación entre Dios y el educador humano donde se alcanza la máxima contribución a la constitución de la persona y se inserta la respuesta a la llamada de Dios a la fe.

Palabras clave: Educación religiosa. Relación empática. Vías de acceso a la fe. Catequesis de adultos.

\section{Introdução}

Este artigo tem por objetivo apresentar a proposta pedagógica de Edith Stein (1981-1942) sobre a formação religiosa aplicada à formação de catequistas para a Catequese com Adultos. Discute o tema da formação, com base na unidade e individualidade da pessoa humana, e destaca a presença da dimensão religiosa e sua imprescindibilidade para o desenvolvimento harmônico e para o seu destino último.

Na obra escrita entre os anos 1932-1933, A Estrutura da Pessoa Humana. Curso de Antropologia filosófica (2013), Stein dialoga com a filosofia de Tomás de Aquino, a fenomenologia de Edmund Husserl e com pensadores alemãs de Lessing a Goethe. Ela também traça um confronto entre a filosofia escolástica e moderna na construção de uma filosofia da educação. Utilizandose do método fenomenológico, esboça uma ontologia da pessoa humana, ou seja, investiga o ser do ente, seu devir na existência, sua enticidade e sua constituição e, mais ainda, o devir do ser de cada ente, seu processo de se tornar indivíduo, que é propriamente a individuação. No caso do ser humano, a individuação é um processo de vir-a-ser do sujeito humano no mundo-davida, pelo qual se encaminha a realização de si mesmo, incluindo os acidentes que esse processo possa ter. A questão do ser perpassa, portanto, o conjunto das obras steinianas nas quais a autora investiga "o que é o homem?", qual é sua essência, sua origem e sua finalidade (télos).

Desse modo, Edith Stein, em seus escritos e, de maneira especial, na $A$ estrutura da pessoa bumana (2013), realça que toda e qualquer prática educativa deve estar pautada numa concepção antropológica, porque "o ser humano é o fundamento da ciência do exercício pedagógico”. Essa ideia constitui a

\footnotetext{
A obra reúne textos escritos por ocasião do curso ministrado em 1932-33, no Instituto de Pedagogia Científica, em Münster, na Alemanha. Edith Stein escolheu como tema do curso $A$ estrutura da pessoa humana, que deveria servir como base teorética para a elaboração de uma filosofia da educação. O termo utilizado pela autora nesse contexto é aquele de Ciências da Educação ou Pedagogia. Seu objetivo era as bases teoréticas para aprofundar a questão da educação como pressuposto necessário para a práxis educativa. Contudo a denominação mais adequada parece ser é aquela de filosofia da educação.
} 
linha norteadora da prática docente, "pois sua peculiaridade se baseará na compreensão do mundo de cada indivíduo e no seu processo de específico de formação" (ZILLES, 2017, p. 370).

Assim, a antropologia é uma disciplina filosófica que se utiliza, também, dos resultados das ciências e, ao mesmo tempo, necessita de uma contribuição da teologia para uma sua elaboração própria. Edith Stein discute, desde seu primeiro escrito, O Problema da Empatia (1992), a constituição da subjetividade humana compreendida na sua totalidade e, também, as implicações desse processo na sua formação e a autoformação. $\mathrm{Na} A$ estrutura da pessoa humana (2013a), ela retoma a filosofia de Tomás, os diálogos metafísicos de Hedwig Conrad-Martius e a fenomenologia de Husserl (1859-1938) para uma sua definição de pessoa humana fundamentada na metafisica cristã.

No âmbito filosofia da educação, Edith Stein insere-se no contexto pedagógico do final do século XIX e início do século XX, período caracterizado por reformas do sistema educacional e de grandes revoluções históricas. Como estava sintonizada com as propostas e tendências do seu tempo, ela participou na luta por modelos pedagógicos voltados para uma educação integral do ser humano (STEIN, 1999). Desse modo, inscreve o conceito de educação (Bildung), típico da cultura alemã, no seu projeto pedagógico. Assim, a formação passa a indicar o resultado da educação. A formação como processo, refere-se ao desenvolvimento, no qual o ser humano conquista uma figura e uma forma, uma precisa identidade. A seguir discutiremos alguns aspectos da pedagogia steiniana.

\section{Proposta Pedagógica em Edith Stein}

A base fenomenológica herdada por Edith Stein de Husserl possibilitalhe a originalidade e a amplitude do processo de formação e de educação (Bildung). ${ }^{2}$ A noção Bildung, afirmada nas palestras e escritos dos anos 1930, encontra-se inserida no livro A vida como totalidade. Escritos sobre educação religiosa (STEIN, 1994). O termo Bildung, por sua vez, refere-se à ação de formar (Bilden), ao processo de ser formado, ou seja, formar uma matéria e criar, desse modo, uma imagem (Bild) ou uma forma. Já o conceito de formação e educação refere-se a uma disposição, inerente ao ser humano, em

\footnotetext{
2 O termo Bildung, de origem alemã, significa formação, ou educação. Essa definição, contudo, supera uma noção apenas imaginária e cultural do termo. Bildung significa formação e educação, tanto no sentido material e quanto no espiritual, portanto, a educação deve conduzir a uma sabedoria de vida e a uma a plena realização de si (STEIN, 1994, nota 1, p. 21).
} 
direção ao seu crescimento e ao progresso interior. Trata-se de uma tensão contínua pela qual cultura e natureza, conhecimento e espírito dão forma e é precisamente pela existência do ser humano que isso acontece. De tal modo, a empatia encontra, no conceito de formação, um território para aprofundar o conhecimento de si mesmo na relação com o outro.

A empatia é apresentada como experiência original de encontro, como itinerário pelo qual o educador é o mediador que possibilita, ao lado da Graça divina, uma educação para a perfeição e responsabilidade com o outro. Assim, a educação, como formação integral, é a diretriz pedagógica para a formação da pessoa. Qualquer prática educativa orientada para a formação humana deve ser sustentada por uma antropologia filosófica e teológica, fio condutor de toda sua investigação steiniana e ponto central de onde partem as práticas e para onde devem convergir. Em tempos em que as ciências humanas estavam em crise, Edith Stein conscientemente propôs uma antropologia, pessoal e educativa, sem a qual não seria possível fazer frente às propostas naturalistas, positivistas, existencialistas e niilistas em vigor.

Edith Stein considera, ao mesmo tempo, que a formação do educador deve apontar para uma vivência do processo formativo e para o desenvolvimento das potencialidades a partir da vocação específica de cada um. A filósofa estuda vários modelos pedagógicos e indica, em seus escritos, a necessidade de propostas específicas de formação. Assegura que todo projeto educativo deve estruturar-se a partir de uma base inovadora, criativa e empática, ou seja, a partir de uma rede de contatos entre colaboradores capazes de promover a "autonomia completa e a autoeducação" (STEIN, 2013, p.18).

Edith Stein, no seu projeto educativo, considera "quem é o ser homem e o ser mulher, o que há de comum na essência humana como base para definir o processo de formação" (STEIN 1999, p. 206). O diálogo com a metafisica escolástica foi particularmente importante para dar uma fundamentação antropológico-filosófica e teológica para a pedagogia. $\mathrm{Na}$ obra Quem é o homem? (2005) ${ }^{3}$, que é uma continuação da $A$ estrutura da pessoa humana (2013a), a autora evidencia a imagem do homem da doutrina cristã. Compreende que é tarefa urgente para o pedagogo católico estar ciente do que a fé ensina sobre a pessoa humana. O projeto científico educativo de Edith Stein tem como horizonte uma antropologia teológica, pois o ato

Está obra está em língua alemã sob o título: STEIN, Edith. Was ist der Mensch?

Theologische Anthropologie. Friburgo na Brisgóvia: Herder, 2005. 
pedagógico essencial começa quando existe a cooperação de Deus. Aquele que está em formação deve conhecer e optar livremente pelo caminho apresentado, então, poderá abrir-se à Graça, para que essa seja eficaz nele. "Aquilo que o ser humano é no seu mais profundo, aquilo que ele é na sua singularidade, deve a Deus e tudo aquilo que deve as comunidades humanas, indiretamente é atribuído a Deus" (STEIN, 2013, p. 217).

Mas qual era o problema que antropologia teológica enfrentava nessa época? O contexto da filosofia alemã era marcado pela posição fenomenológica de Heidegger de caráter ontológico e de busca das determinações essenciais do ser dos entes. A paradoxalidade da posição de Heidegger consistia em derrubar um começo promissor, aquele referente ao retorno da questão do ser da filosofia novecentesca, o niilismo, traindo, dessa forma, tanto o presente - a intenção da análise fenomenológica quanto o passado - a validade da investigação metafísica. Marca específica desse contexto era do positivismo e a sua influência na repartição do saber e na definição das disciplinas correspondentes. Esta questão constitui o eixo das pesquisas e produções filosóficas de Edith Stein a começar pela tese de doutorado sobre a empatia. Ela reflete sobre a pessoa humana indissociável da sua busca de sentido e orienta-nos sobre a sua proposta educativa a partir do núcleo da pessoa, ou seja, da formação da consciência, da liberdade e da responsabilidade.

\section{Pessoa humana: subjetividade e intersubjetividade}

Para Edith Stein, a pessoa humana é um todo constituído pela sua unidade e individualidade, composto por corpo, psique e espírito. Essa questão é discutida pela filósofa, a começar na sua tese de doutorado $O$ problema da empatia (1992) e nas suas investigações sobre a psicologia humana na Psicologia e ciências do espírito, contribuições para fundação filosófica (1996). Com o apoio do método fenomenológico, busca o conhecimento objetivo das coisas na constituição da consciência e na sua intencionalidade, por meio das vivências. Assim, o método fenomenológico coloca-se na vivência como fonte do conhecimento. Nessas obras, emerge o conhecimento da pessoa humana. Primeiramente, ocorre no sentido individual; depois, na ampliação para a esfera da comunidade (família, Igreja, escola etc.) sociedade e estado.

Desse modo, por um lado, Stein supera o idealismo kantiano, que havia levado o conhecimento a tornar-se independente da subjetividade humana, e o solipsismo, ou seja, a concentração de toda a realidade "somente no 
sujeito"; por outro, o empirismo, na sua versão mais radical, o positivismo, que levava a filosofia da ciência a uma redução material.

O método fenomenológico representava uma novidade enquanto garantia a objetividade das coisas no mundo (real empírico), quanto à representação destas na subjetividade da consciência (ideal mental), elegendo um terceiro elemento neutro para o conhecimento, que é o conceito de constituição (ANDREATA, 2019, p. 137).

Tendo esclarecido isso, Stein introduz a empatia como via de acesso ao mundo do outro e modo de conhecimento de si mesmo, ou um outro eu. A empatia, filosoficamente, aponta a questão da ipseidade (ipsum, idem) e da alteridade, ou seja, da identidade de si diante da diferença do outro, que constantemente o ser humano propõe-se à consciência. A empatia, indica também a possibilidade de conhecimento da subjetividade por meio da intersubjetividade, que aponta para uma realidade de "um outro de nós", no centro da estrutura da personalidade (si-mesmo).

No início do desenvolvimento da tese de doutoramento, Stein diz: "Na base de toda a controvérsia sobre a empatia subjaz um pressuposto tácito: nos estão dados sujeitos outros e suas vivências" (STEIN, 1992, p. 53). Isso equivale colocar como hipótese a verificação de como a empatia pode servir de meio ao conhecimento do outro que se dá independente de mim. Os sujeitos empáticos são compreendidos como pessoas espirituais, pois são constituídas de espírito, além de alma e corpo. Edith Stein, "com isso mostra o valor que a análise da hilética poder ter para o significado mais profundo da experiência sacro-religiosa, sobretudo com a finalidade de compreender o significado" (PERETTI, 2019, p.111) da dimensão religiosa, e do sagrado presentes na nossa vida cotidiana.

A empatia, como um ato de vivência autônomo, possibilita colher a experiência alheia, tal como um "dar-se conta", "um notar" ao outro, mas na base da empatia está sempre a percepção, ou seja, a empatia é um ato cognoscitivo e não meramente emocional. Os sujeitos empatizados, portanto, mantêm suas individualidades (ALES BELLO, 2014, p. 54; SAVIAN Filho 2014, p. 33). Na relação intrapessoal e interpessoal, a pessoa estrutura si mesma, isso é, torna-se si mesma por meio do outro. Na raiz do conceito Einfüblung (füblung), Stein aponta o fecho de todas as suas obras - o sentir a si mesmo em Deus (ANDREATA, 2019).

No conceito de empatia (uma vivência sui generis), é que se tem a 
compreensão do outro como um ser que é portador de uma vida espiritual e psicofísica, particular em cada ser humano. Essa particularidade permite a cada um apreender aquilo que é próprio da sua estrutura humana e, por meio da relação com o outro, perceber que ele é semelhante, mas não idêntico. $\mathrm{O}$ encontro com o outro revela um dado muito importante: o "Leib", ou seja, o corpo próprio, o corpo vivente. Assim, Leib é um termo alemão que se refere a uma corporeidade que não é apenas matéria física, mas também um corpo vivente. O Leib é o fundamento, a expressão e o instrumento da alma espiritual e é a condição para a existência da alma neste mundo.

O ser humano, de fato, é um ser que se distingue de todos os outros seres. Tem vivência própria e sentimentos ímpares. As vivências psíquicas, na grande maioria, passam pelas vivências corporais e exteriorizam-se como fenômenos que são perceptíveis em si mesmo e nos outros. É nas relações intrapessoais e intersubjetivas que emergem as vivências. Nós temos vivências internas e externas. O território da psique mostra o que acontece em nós, está dentro de nós e que não é corpo. Indica um processo de liberdade que só o ser humano, dentre os seres vivos, experimenta.

Peretti e Dullius (2018, p. 158) afirmam: "Toda consciência e expressão da alma, acontece e se expressa a partir do corpo físico”. Sem a alma, o corpo é somente um cadáver. Todas as sensações sentidas pelo corpo estão intimamente conectadas pela percepção psíquica e espiritual do homem em tudo aquilo que vive e expressa. $\mathrm{O}$ ser humano tem um corpo vivente, pois tem matéria e tem psique. É próprio da vida psíquica "aproximar o mundo animal do mundo humano" (SBERGA, 2014, p. 117). O ser humano é capaz de perceber a si mesmo e ao outro como, também, é capaz de se perceber dentro de si mesmo e de tomar decisões diante de tudo o que ocorre dentro e fora dele. É um ser livre pela sua própria natureza. A propósito disso, Stein afirma que:

Quando olho um homem nos seus olhos, seu olhar me responde. Permiteme penetrar em seu interior ou, em outro caso, me rechaça. É senhor de sua alma e pode abrir ou fechar suas portas. Pode sair de si mesmo e entrar nas coisas. Quando dois homens se olham, estão frente a frente de um eu e outro eu. Pode tratar-se de um encontro no interior, o outro eu é um tu. O olhar do homem fala. Um eu dono de si mesmo e desperto me olha desde esses olhos. Disse-se também: uma pessoa livre e espiritual. Ser pessoa quer dizer ser livre e espiritual. Que o homem é pessoa, isto é o que o distingue de todos os seres da natureza (STEIN, 2003, p. 648). 
A dimensão espiritual do ser humano permite-lhe ter clareza diante de suas escolhas e, mediante seu livre arbítrio, pode escolher entre o bem e o mal, ser bom ou mau, diferentemente dos animais e das plantas que agem segundo a sua própria natureza. O espírito remete àquilo que é especificamente humano e mostra que o ser humano possui algo a mais do que as outras espécies. Com efeito,"spiritus indica algo da alma, ou seja, que o ser humano tem algo em si que não é o corpo e que se aproxima de outras realidades, como a de Deus, que é o Espírito por excelência, ou dos anjos, que são espíritos puros finitos" (SBERGA, 2014, p. 121). Na cultura alemã, geist tem uma conotação mais ampla que intelecto e vontade. Geist é a potência da alma" (SBERGA, 2014, p. 121). Em Edith Stein, o espírito ganha conotação espiritual (geist, em alemão) que significa abertura para aquilo que é totalmente espiritual. É o espírito quem permeia o fluxo das vivências e a vida espiritual está sustentada pelos atos de vontade.

Convém ressaltar que é o espírito que possibilita, ainda, estabelecer relações comunicativas com os outros seres humanos, realizar atos de conhecer, amar e transcender a si mesmo e de realizar uma vivência no próprio corpo e na própria psique. Essa relação possibilita estabelecer uma harmonia entre o corpo e a psique. O espírito faz emergir algo novo dentro de si mesmos e ir além, permite "uma abertura em uma dúplice direção: ao mundo objetivo a ser experienciado, à subjetividade de outrem, ao espírito alheio, junto de quem se experiencia e se vive" (PERETTI; DULLIUS, 2018, p. 162).

Essa busca do sentido do ser levou Stein até o primeiro ser: ao "ser em pessoa", e o ser em três pessoas, ou seja, a Trindade. A esse ponto, ela define "o espiritual como o não espacial e o não material; como o que possui um 'interior' em um sentindo completamente não espacial e permanente 'em si", enquanto sai de si mesmo" (STEIN 2019, p. 384). Na Trindade, ou seja, na entrega total de si às pessoas divinas, "na qual cada uma se priva inteiramente de sua essência, e, no entanto, conserva perfeitamente, cada uma está inteiramente em si mesma e inteiramente nas outras, temos diante de nós o espírito em sua realização mais perfeita" (STEIN 2019, p. 384-385).

Para Stein, o ser humano realiza-se à medida que é capaz de se adentrar na vida interior. Quando está na sua alma, em sua casa, "é um ser consciente; o eu, um ser desperto, cujo olho espiritual olha para o interior e para o exterior: pode assumir compreendendo tudo o que vai até ele, responder em liberdade pessoal, de tal ou qual maneira" (STEIN, 2019, p. 
384-385). No núcleo interior - "alma da alma" -, o eu, encontra a capacidade de desenvolver seus atos psíquicos e espirituais, sua individualidade e singularidade. "Há uma intrínseca relação entre o psíquico, o espiritual e a corporeidade, pois a força espiritual que se manifesta na psique precisa do corpo físico para se exteriorizar" (PERETTI, DULLIUS, 2018, p. 162).

\section{Formação religiosa e vias de acesso a fé}

A dimensão espiritual dá ao ser humano a capacidade de se abrir para o mundo-da-vida e para as vivências, pois a vida espiritual brota sempre de novos sentidos e não descansa até que não encontra Deus para nele fixar sua morada. Aplicando esses princípios ao processo de Iniciação à Vida Cristã de Adultos, com inspiração catecumenal, ressalta-se que o sentido de sua existência realiza-se na comunhão estreita entre Deus e a alma. De fato, a finalidade da catequese "é uma educação da fé das crianças, dos jovens e dos adultos, a qual compreende especialmente um ensino da doutrina cristã, dado em geral de maneira orgânica e sistemática, como fim de os iniciar na plenitude da vida cristã" (CIgC 5). O itinerário catecumenal de adultos requer o envolvimento de toda a comunidade e dos catequizandos na participação da vida comunitária e no engajamento na sociedade (CNBB 107).

Quanto aos métodos, a Igreja não possui um método único e próprio para a transmissão da fé, mas assume métodos contemporâneos na sua variedade e riqueza, sempre respeitando integralmente os postulados de uma antropologia cristã e a fidelidade ao conteúdo da fé. Utiliza-se, também, das ciências pedagógicas e da comunicação, levando em conta as especificidades da educação da fé (DNC 150), as experiências e os desafios vividos pelos catequizandos (DGC 172):

O itinerário catecumenal com os adultos, exige uma catequese adequada aos diferentes perfis: adultos crentes, que vivem sua fé e apresentam o desejo de aprofundá-la; adultos batizados, que não foram suficientemente evangelizados ou se distanciaram da fé, podendo mesmo até ser chamados de 'quase catecúmenos' e adultos não batizados, aos quais corresponde o verdadeiro e próprio catecumenato. Ademais, devem ser mencionados os adultos advindos de confissões cristãs que não estão em comunhão com a Igreja Católica.

Assim, formar catequistas, para a Catequese com Adultos, significa entrar num processo de amadurecimento e de adultescência: uma tarefa permanente, dinâmica, em vista do cultivo da fé, colocada por Deus no coração do ser humano. É na perspectiva da vida de fé que se situa a 
“formação religiosa”, considerada por Edith Stein como "a parte mais importante da educação" (RUS, 2015, p.106), e cuja finalidade é abrir o caminho que conduz a Deus. É preciso, portanto, cultivar uma fé viva que conheça, ame e sirva a Deus. Essa fé é despertada não por um ensino intelectual árido e fanático, mas por uma formação que põe “em comunhão com Jesus Cristo: somente Ele pode levar ao amor do Pai, no Espírito, e fazer-nos participar na vida da Santíssima Trindade" (CIgC 426).

\section{Jesus Cristo: finalidade da educação}

A fé abre o ser humano para o anúncio de Jesus Cristo, para levar à fé n'Ele. A fé constitui a pedra angular de uma abertura à própria Verdade, acolhida como mistério e plenamente reconhecida na pessoa de Jesus Cristo que é a revelação corporal de Deus. E, ainda, a fé dá acesso ao Deus pessoal e próximo, que coincide com a plenitude do sentido. Pela fé, o ser humano encontra, em Cristo, o "Logos", fundamento de toda a sua existência, e "nele, a essência divina conhecida (a 'imagem do Pai') e o arquétipo e a causa primeira de toda o criado" (STEIN, 2019, p. 374).

Para Stein, a pedagogia necessita da fundamentação natural e sobrenatural, de modo que ela mantenha um vínculo estreito com a teologia, sem que se converta nela. Desse modo, educar para a fé significa conhecer a verdadeira natureza humana, sua imagem ideal, em que um olhar simplesmente humano não pode penetrar inteiramente. Por essa razão, é legítimo abrir-se para a Revelação, contemplar a vida de Jesus para agir como Jesus. O que Deus quer concretamente de nós, na nossa vida, na nossa história, é-nos revelado contemplando a vida do Jesus histórico, isto é, contemplando a história de Jesus. (BARREIRO, 2003).

Os discípulos de Jesus, desde o princípio aderiram no desejo de anunciar Cristo: "Nós é que não podemos deixar de dizer o que vimos e escutamos" (At 4, 20). E convidam os homens de todos os tempos a entrar na alegria da sua comunhão com Cristo:

O que ouvimos, o que vimos com os nossos olhos, o que contemplamos e as nossas mãos tocaram acerca do Verbo da vida, é o que nós vos anunciamos, pois a vida manifestou-Se e nós vimo-la e dela damos testemunho: nós vos anunciamos a vida eterna que estava junto do Pai e nos foi manifestada. Nós vos anunciamos o que vimos e ouvimos, para que estejais também em comunhão conosco. E a comunhão em que estamos é com o Pai e com o seu Filho, Jesus Cristo. E escrevemos tudo isto para a nossa alegria ser completa (1 
Jo, 1, 1-4) (CIgC 425).

Educar, catequizar é, portanto, revelar, na Pessoa de Cristo, Verbo Encarnado e Filho de Deus, todo o desígnio eterno de Deus. É levar ao reconhecimento da Pessoa de Cristo, compreender os significados dos gestos, das palavras e dos sinais por Ele realizados. Mais ainda, "todo o catequista deveria poder aplicar a si próprio a misteriosa palavra de Jesus: "a minha doutrina não é minha, mas d'Aquele que Me enviou” (Jo 7, 16"). (CIgC 427).

Todo aquele que é chamado a "ensinar Cristo" deve, portanto, inicialmente, conhecer Jesus Cristo.

Tem de 'aceitar perder tudo [...] para ganhar Cristo e encontrar-se n'Ele" e "conhecê-Lo, a Ele, na força da sua ressurreição e na comunhão com os seus sofrimentos, conformar-se com Ele na morte, na esperança de chegar a ressuscitar dos mortos ( $\mathrm{Fl} \mathrm{3,8-11).}$

Desse conhecimento amoroso de Cristo brota o desejo de anunciá-Lo, de "evangelizar" e levar os outros ao "sim" da fé em Jesus Cristo. Mas, ao mesmo tempo, faz-se sentir a necessidade de conhecer sempre melhor esta fé" (CIgC 428).

\section{A Pedagogia de Jesus e a resposta à fé}

O amor é a chave da vida e da mensagem de Jesus, assim como de seus discípulos. Mais que uma ética, o amor é a base daqueles que, de uma forma ou de outra, pertencem ao grupo de Jesus de Nazaré (Jo 13,34-35). Os evangelhos desvelam-nos o coração e os sentimentos de Jesus. Como homem, Jesus estava perto daqueles que o procuravam, podiam sentiLo, prestava atenção aos detalhes das vivências das pessoas, valorizava e estimulava. Sabia amar.

Jesus não se envergonhava de se manifestar=se abertamente: Disse Marta: "Sim, Senhor, eu creio que tu és o Cristo, o Filho de Deus que vem ao mundo" (Jo 11,27). Ele é um amor que perdoa, que renuncia a condenar o pecador, como no exemplo da "A mulher adúltera" (Jo 8,1-8). É um amor compassivo com as debilidades e fraquezas dos outros:

Vinde a mim todos os que estais cansados sob o peso do vosso fardo, e eu vos darei descanso. Tomai sobre vós o meu jugo e aprendei de mim, porque sou manso e humilde de coração, e encontrarei descanso para as vossas almas, 
pois o meu jugo é suave e o meu fardo é leve (Mt 11, 28-29).

Jesus também possui: um amor desinteressado em relação aos próprios inimigos (Lc 23,34); um amor ativo, que corrobora as palavras de admiração com gestos de vizinhança (Lc 4, 31-37); um amor forte até o último sacrifício, porque ninguém tem maior amor do que o que dá a vida por seus amigos (Jo 15,13); um amor revelador de sua presença na pessoa do faminto e do marginalizado (Mt 25, 31-46).

Dessa maneira, Jesus faz-se próximo de todos e convida seus discípulos a serem perfeitos (Mt 5,48), a serem misericordiosos (Lc 6,36), a acolher a todos (Mt 25, 31-46). Ser cristão, portanto, é pensar e viver segundo o ideal de pessoa humana traçado por Jesus, sua forma de viver e ensinar o amor. No encontro com a Samaritana, Jesus deixa um exemplo insuperável de encontro empático: aproxima-se e dialoga com a mulher. A samaritana identifica Jesus como Messias, reconhece-o e declara: Ele é o Salvador e, consequentemente, torna-se missionária. Nesse encontro, a mulher disse a Jesus: "Senhor, dá-me dessa água, para que eu não tenha mais sede, nem tenha de vir aqui tirar água" (Jo 4,15). Esse encontro mostra a vitória do Evangelho sobre os preconceitos socioculturais. A samaritana era apenas uma mulher comum e não tinha conhecimento bíblico, mas foi capaz de reconhecer Jesus, o Messias. A capacidade de Jesus de escutá-la fez aumentar nela o desejo de estar com Ele. É nisso que consiste a força do ato pedagógico. A pessoa converte-se no que foi chamada a ser, não obstante os obstáculos.

Os gestos de Jesus possibilitam compreender que é o amor que define a fé cristã e a caridade remete à forma como se colocar a serviço e à disponibilidade em favor dos outros $(\mathrm{Gl} 5,13)$. Trata-se de: um amor prático (G1, 5,6; 2Cor 8,8-11.24); um amor que se dedica à ajuda mútua, sem buscar seu próprio interesse (Ef 4,2); um amor que é capaz de partir, como o de

Jesus, do esquecimento e do dom de si aos irmãos (Fl 2,4). É, portanto, no doar-se contínuo e no encontro com o outros que a fé em Jesus encontra sua máxima expressão.

\section{Empatia e educação para a fé}

A abertura à Verdade Revelada faz-nos encontrar a imagem concreta da natureza humana em sua completude tal como ela manifestou-se entre nós na Pessoa de Jesus Cristo. No cristianismo, a Evangelização faz o primeiro anúncio da Boa-Nova de Jesus Cristo, anuncia Jesus; a catequese trabalha o 
anúncio em forma de educação da fé, suscitando e levando a ação pastoral com os fiéis já iniciados na fé e incorpora-os na comunidade cristã, por meio de formação continuada. A incorporação a Cristo e a participação do catecúmeno na vida de Cristo requer do catequizando experiência e aprofundamento do conteúdo da fé. Enfatiza-se, deste modo, a relevância da empatia como possibilidade de compreender o ser humano e o caminho por ele escolhido.

A empatia aponta para a relação e a compreensão do outro; indica a possibilidade de conhecimento do outro por meio da relação intersubjetiva. Portanto, em linguagem fenomenológica, a empatia pressupõe o dar-se do sujeito de forma intencional e consciente. A raiz grega do termo én-pátheia indica a vivência de um sentimento (páthos, sentir) em direção "para dentro" (én, em/dentro), da subjetividade (bypokéimenon) de um "sujeito", que, conforme o sentido duplo de intencionalidade pode ser mutuamente tanto "para dentro do sujeito-eu" como "para dentro do sujeito-outro". (STEIN, 1992, p.51).

Encontramos, na filosofia de Edith Stein, elementos importantes para o itinerário catequético e para colher os aspectos fundamentais que caracterizam a vivência da fé e das dimensões espirituais que transcendem o tempo e o espaço. A empatia apresenta-se como elemento fundamental do método fenomenológico para a compreensão aspectos da vivência interior, que não são apreendidos por meio de recursos técnicos, mas no encontro com o outro, na escuta e no diálogo. A essência da fenomenologia é o "retorno às coisas mesmas", que se faz através da observação como as coisas do mundo-da-vida "aparecem", ou "manifestam-se" para a consciência percipiente.

A proposição do método fenomenológico, para a formação de catequistas, parece-nos inovadora para uma catequese de inspiração catecumental e para fundamentar o itinerário formativo para o catequista. Edith Stein recupera, na sua visão pedagógica, um axioma fundamental: "a vida interior é o fundamento último, a formação se faz do interior para o exterior" (RUS, 2015, p. 47). Educar significa levar para fora de, fazer sair de, e é por isso que se trata de falar de um gesto, que, por sua vez, remete a um movimento irradiante a partir do interior.

A formação do catequista fundamenta-se no serviço de uma missão que consiste na manifestação da vida interior. Isso acontece ainda melhor se os elementos que compõem o gesto educativo fundem-se, de maneira unificada, num gesto epifânico, pelo qual uma existência toma corpo na sua unicidade manifesta (RUS, 2015, p. 47). Logo, “a missão do educador contribui para 
a obra de salvação na medida em que ele se submete à vontade divina e se faz instrumento da ação de Deus no mundo, num verdadeiro trabalho de colaboração" (KUSANO, 2014, p. 140). O gesto educativo confere sentido à vida escondida nos segredos da alma. Isso ocorre porque cada pessoa possui em si uma motivação necessária para se desenvolver numa determinada direção. Cada pessoa, em virtude de sua individualidade, está envolvida num processo de atualização das características constitutivas da sua personalidade. Assim, no itinerário educativo, a racionalidade, a liberdade e a vontade são características fundamentais para a destinação natural e sobrenatural da pessoa, que possui em germe a tendência para a transcendência.

Para Stein "[...] cada pessoa se designa a si mesma como tal, é "eu". (STEIN, 2019, p. 365). "Isso quer dizer que se trata de um eu presente que vive em cada "eu percebo, "eu penso", "eu concluo", "eu me alegro", “eu desejo etc.”. (STEIN, 2019, p.75). E, ainda, para Stein: "só pode chamarse "eu" um ente que em seu ser é consciente de seu próprio ser e, ao mesmo tempo, de seu ser diferente, distinto de outro ente. Cada eu é algo único e possui algo que não reparte com nenhum outro ente, ou seja, algo incomunicável, [...] é único”. (STEIN, 2019, p. 365-366).

Diante disso, considera-se que a pedagogia steiniana fundamenta-se sobre "uma ontologia da pessoa", ou seja, sobre o devir da pessoa na sua existência, na sua eticidade e na sua constituição. Essa ontologia leva em conta a espiritualidade da pessoa e considera a pessoa sob uma natureza triuna de mente, corpo e espírito. Stein descreve, nas suas primeiras obras, as formas de acesso ao outro e de compreensão da estrutura ôntica (interior) e ontológica (exterior), da pessoa humana, tanto em sua dimensão individual quanto coletiva comunitária. Observa que a alma humana não é só forma interior que dá sustentação ao corpo. Ela dá forma a ele, orienta e apreende aquilo que se dá na sua interioridade ou que pode dar-se. A alma é intelectiva, é espírito; a alma possui uma existência própria e superior àquela do corpo. Diferentemente do corpo, que necessita de substâncias materiais para se desenvolver, a alma necessita de substâncias espirituais (STEIN, 1994, p. 25). Da possibilidade da existência individual de um sujeito com seu mundo subjetivo, que pode conhecer as coisas e comunicar o que conhece, a partir de um "núcleo" (como centro, "si mesmo") próprio que lhe dá autonomia, constitui-se o conceito de alteridade na ontologia steiniana.

Compreende-se, assim, que o mistério da educação é, também, o mistério do ser humano. A pedagogia steiniana estrutura-se com base na 
antropologia filosófica e na ontologia e tem por finalidade conduzir o ser humano criado e redimido no encontro com Deus e na realização de si mesmo. Todo projeto educativo deve contemplar a essência do sujeito (aquilo que ele é) e a sua missão (aquilo que é chamado a ser com base na sua essência. Ponto de partida e, ao mesmo tempo, de chegada é "aquilo que a fé nos propõe como fim do ser humano", ou seja, o cumprimento da obra da criação e da redenção" (STEIN, 2019, p. 374).

A tarefa pedagógica na educação para a fé consiste, portanto, em conduzir homens e mulheres

à vida interior, a um ser consciente, desperto, cujo olho espiritual olha para o interior e para o exterior: pode assumir compreendendo tudo o que vai até ele, responder em uma liberdade pessoal, de tal ou qual maneira. Pode-o e porque o pode, o homem é uma pessoa espiritual, suporte de sua vida no sentido eminentemente do pessoal 'ter-se em mãos' (STEIN, 2019, p. 393-394).

Mas, para o ser humano, existe um âmbito da liberdade que coincide com toda a envergadura do seu ser. A alma é o centro, a mediação entre a espiritualidade e sensibilidade. A vida espiritual brota do entrelaçamento entre espiritualidade e sensibilidade. Com isso, compreende-se que na base da experiencia religiosa está a experiência vital. "É nela que a graça age" e santifica. De fato, "a experiência humana é o âmbito de manifestação e de realização da Salvação, onde Deus, coerentemente com a pedagogia da encarnação, alcança a pessoa com sua graça e a salva" (DGC 152). Para tanto, a escuta empática é fundamental no âmbito da experiência vital do catequizando adulto. Ajudar o catequizando a perceber como o desejo de Deus e do bem se manifestam contribui para harmonizar o si mesmo em Deus (DNC, 165).

Nesse sentido, a formação religiosa não se resume no conhecimento da verdade pela verdade, mas amplia-se pela intersubjetividade, na força motivacional presente no núcleo do ser, que conduz ao sentido, fortalece a vontade, ilumina o entendimento e remete a valores eternos. Edith Stein sustenta que "é preciso uma luz sobrenatural para chegar ao conhecimento do mistério”. (PERETTI; DULLIUS, 2018, p.47). Ao conhecer e optar livremente pelo caminho da fé, a pessoa abre-se livremente à Graça. A essa forma de vida, Stein contrapõe outra, denominada por ela com a vida dona de si mesma, uma etapa intermediária entre a alma em seu estágio animal e a alma plenamente livre vivificada pela Graça (STEIN, 2013a). Desse modo, 
a pedagogia steiniana é cunhada na integralidade da pessoa humana com envergadura na dialógica entre singularidade e empatia, interioridade e exterioridade, natureza e graça, finitude e eternidade. Contribui, assim, para uma educação que visa não somente o tangível, mas, permite uma abertura para o Transcendente (PERETTI; DULLIUS, 2018, p.48).

É pelas verdades da fé que se obtém um conhecimento mais pleno e real do ser humano. Se a pedagogia não se fundamentar na Revelação, corre um sério risco de não considerar o ser humano aquilo que ele é na sua essência: arquétipo de Deus. Nisso consiste a tarefa do catequista: conduzir o ser humano a ser o que ele é; a ter-se nas próprias mãos; a entrar na sua própria interioridade e, aí fazer morada com Deus. O homem necessita da Graça e, segundo a tradição judaico-cristã, o Espírito Santo é formador/ educador" e ocupa uma parte essencial nesse processo.

\section{Considerações}

Para Edith Stein, o desenvolvimento humano, psíquico e espiritual deveria dar-se contemporaneamente. "A alma, em seu interior, experimenta a regeneração e o influxo de uma força, não pelo efeito dos bens espirituais que provém do mundo externo, mas, através da graça, princípio formativo, revivido na fonte de todo ser e de toda a vida" (STEIN, 1994, p. 26).

A proposta pedagógica de Edith Stein está centrada na esfera da antropologia filosófico-teológica e da ontologia da pessoa humana. Eu, alma, espírito e pessoa estão estritamente interconectados no itinerário formativo: cada palavra possui um seu sentido especial que coincide inteiramente com o da outra. "A vida do eu desperta e consciente é, o caminho de entrada à alma e à sua vida oculta, como a vida dos sentidos é o caminho do acesso, visto que é uma manifestação do que acontece na alma e uma repercussão da sua essência” (STEIN, 2019, p. 397). A alma não pode viver sem receber, pois ela se nutre-se do que recebe, vivenciando, espiritualmente, assim como o corpo nutre-se de matérias que o transformam. Cada pessoa possui uma sua própria individualidade marcada com o selo de uma unicidade pessoal, de uma "nota própria" que a educação deve levar em consideração de modo a favorecer o desenvolvimento de "uma personalidade que possui sua especificidade totalmente individual e determinada" (RUS, 2015, p. 54).

A formação é o resultado da coparticipação da pessoa a partir da sua interioridade, mas essa não é apenas fruto da ação humana, mas também da ação da graça. A pessoa é livre de aceitar a graça e de se abrir para responder 
ao chamamento da fé. Para Stein, a pessoa tem um "núcleo" de onde emana a verdade de si mesma, um centro a ser ouvido, conhecido, acolhido como fonte de autenticidade e unicidade, como portador de uma verdade sobre a pessoa a ser revelada e uma estrutura da pessoa a ser respeitada e formada. "A possibilidade de mover-se dentro de si mesma funda-se nesta qualidade: a alma é um EU. [...]. O Eu é o que lhe permite decidir sobre si própria” (STEIN, 2013b, p. 134). O grande mistério que constitui a liberdade da pessoa é que o próprio Deus respeita sua liberdade. "Apenas pela oferta generosa de amor, por parte dos espíritos criados, é que Deus quer dominá-los. Ele conhece os "pensamentos do coração", penetra os mais profundos abismos da alma onde nem ela pode penetrar sem iluminação divina: entretanto, Deus não quer dela se apoderar sem que ela o consinta" (STEIN, 2013b, p. 135). Deus não quer dominar os espíritos criados a não ser pela entrega livre que eles fazem do seu amor.

O ser humano possui uma natureza limitada, por sua própria condição natural (o pecado original), pela sua limitação racional e psíquica e pela necessidade da graça que é o que lhe dá a plenitude. O gesto educativo se faz aliança no encontro entre os esforços divinos e a graça divina. "A educação alicerçada na ação humanizadora conduz a pessoa para além da intelectualização, permite o acesso aos valores universais e eternos" (PERETTI; DULLIUS, 2018, p. 48). O mundo espiritual plasma toda a realidade criada, e essa se fortalece por meio da livre contribuição que cada ser humano oferece de si mesmo em contato com o "centro da alma" (STEIN, 2019 p. 395-396).

Logo, "a educação aparece, como lugar de uma aliança restaurada entre os esforços do ser humano e ação da graça divina” (RUS, 2015, p. 96), Podese afirmar, contudo, que o maior educador humano não é o ser humano, mas Deus. É nesta relação entre o maior Educador com o educador humano que se alcança a máxima contribuição da constituição da pessoa humana. Enfim, é preciso educar para o sobrenatural, pois a educação, para Stein, é concebida como processo de verticalização do ser humano em direção à transcendência e de verticalização em direção ao outro. Deste modo, sua visão educativa merece ser qualificada de mística, no sentido de que o mistério do ser humano enraíza-se no mistério de Deus, revelado em Cristo. O critério último do valor da pessoa humana não consiste no que ela faz em favor da comunidade, da família, do povo e da humanidade, mas segue o chamamento de Deus, que é o conformar-se com Cristo. 


\section{Referências}

ALES BELLO, Angela. A paixão pela verdade. Tradução José Queiroz. Curitiba: Juruá, 2014.

ANDREATA, Ocir de Paula. A individuação da pessoa na ontoteologia de Edith Stein. Ocir de Paula Andreata; Orientadora, Clélia Peretti - 2019. Tese (doutorado) Pontíficia Universidade Católica do Paraná: Curitiba, 2019, $281 \mathrm{f}$.

BARREIRO, Álvaro. Contemplar a vida de Jesus. Prática e frutos. 2.ed. São Paulo: Edições Loyola: 2003.

CNBB. Diretório Nacional de Catequese. Brasília: Edições CNBB, 2005.

CNBB. Iniciação à Vida Cristã: Itinerário para formar discípulos missionários. Brasília: Edições CNBB, 2017 (Documento 107).

CONGREGAÇÃO PARA O CLERO. Diretório Geral para a Catequese. 4. ed. São Paulo: Paulinas, 1998. 4.ed., 2003.

JOÃO PAULO II. Papa. Catecismo da Igreja Católica. São Paulo: Edições Loyola, 2000.

KUSANO, Mariana, Bar. A antropologia de Edith Stein. Entre Deus e a filosofia. São Paulo: Ideia \& Letras, 2014.

PERETTI, Clélia. DULliUS, Vera Fátima (orgs.). A Arte de Educar por uma Pedagogia Empática em Edith Stein. 1. ed. Curitiba: Editora Prismas, 2018.

PERETTI, Clélia. Nas trilhas de Edith Stein. Gênero em perspectiva fenomenológica e teológica. 1.ed. Curitiba: Appris, 2019.

RUS, Eric de. A Visão Educativa de Edith Stein: aproximação a um gesto antropológico integral. Tradução: Isabelle Sanchis et al.; revisão técnica: Juvenal Savian Filho. Belo Horizonte: Editora Artesã Ltda, 2015.

SAVIAN FILHO, Juvenal. A empatia segundo Edith Stein: pode-se empatizar a "vivência" de alguém dormindo? São Paulo: Loyola, 2014.

SBERGA, Adair Aparecida. A Formação da pessoa em Edith Stein. São Paulo: Paulus, 2014.

SILVA, Nara Helena Lopes Pereira da; CARDOSO, Cármen Lúcia. Contribuições da fenomenologia de Edith Stein para a atuação do psicólogo nos Núcleos de Apoio à Saúde da Família. NASF. Revista Latinoamericana de Psicopatologia Fundamental, 16 (2), São Paulo, junho. 2013, p. 246-259. Disponível em: https://doi.org/10.1590/S141547142013000200005. Acesso em: 20 maio 2020.

STEIN, Edith. Obras Completas, IV. Escritos Antropologicos e Pedagogicos (Magisterio de Vida Cristiana: 1926-1933). Bajo la dirección de Julen Ulzika y Javier Sancho. Traduzido do alemão por Francisco Javier Sancho, Constantino Ruiz Garrido, Carlos Díaz, Alberto Pérez, OCD e Gerlinde Follrich de Aginaga. Burgos-Espanha: Editora Monte Carmelo, 2003.

STEIN, Edith. L'empatia di Edith Stein. A cura di Michele Nicoletti. Presentazione di Achille Ardigó. 2. ed. Milano: Franco Angeli, 1992.

STEIN, Edith. La vita come totiltà. Scritti sull'educazione religiosa. Introduzione di Lucy Gelber. Traduzione dal tedesco di Teresa Franzosi. Roma: Città Nuova Editrice, 1994. 
STEIN, Edith. Psicologia e Scienze dello Spirito. Contributi per una fondazione filosófica. Presentazione di Angela Ales Bello. Traduzione di Anna Maria Pezzella. Roma: Città Nuova Editrice, 1996.

STEIN, Edith. A mulher. Sua missão segundo a natureza e a graça. Tradução Alfred j. Keller. Bauru, São Paulo: Editora da Universidade do Sagrado Coração de Jesus, 1999.

STEIN, Edith. Was ist der Mensch? Theologische Anthropologie. Friburgo na Brisgóvia: Herder, 2005. (Edith Stein Gesamtausgabe (15).

STEIN, Edith. La struttura della persona umana. Corso di antroplogia filosofica. Traduzione dal tesdscto. Michele D'Ambra. Revisione della traduzione sulla base de testo della ESGA (Edith Stein Gesamtausgabe) a cura di Anna Maria Pezzella e Marco Paolinelli. Roma: Città Nuova: Edizioni OCD, 2013a.

STEIN, Edith. Ser finito e ser eterno. Coordenação João Ricardo Moderno; tradução Zaíra Célia Crepaldi. 1. ed. Rio de Janeiro: Forense Universitária, 2019.

STEIN, Edith. A Ciência da Cruz. Escritos sobre São João da Cruz. 7. Ed. Tradução D. Beda Kruse. São Paulo: Edições Loyola, 2013b.

ZILLES, Urbano. Notas sobre o Conceito de Pessoa em Edith Stein. In: MANHFOUD, Miguel, SAVIAN FILHO, Juvenal (orgs.). Diálogos com Edith Stein: filosofia, psicologia, educação. São Paulo: Paulus, 2017.

Submetido em: 15-6-2020

Aceito em: 14-8-2020 